\title{
PREDICTED DIURNAL VARIATIONS OF ELECTRON DENSITY FOR THREE HIGH-LATITUDE INCOHERENT SCATTER RADARS
}

\section{J.J. Sojka and R.W. Schunk}

\author{
Center for Atmospheric and Space Sciences \\ Utah State University \\ Logan, Utah 84322
}

Abstract. We have used a high-latitude ionospheric model to predict the diurnal variations of electron density that should be observed by the EISCAT, Chatanika and Millstone Hill incoherent scatter facilities. Our calculations were for a strong convection model without substorms. Our results provide an indication of the quantitative differences in measured electron density that are expected when the three radars probe the high-latitude ionosphere simultaneously. The differences are significant and vary with altitude, latitude, local time, and season, and are associated with the UT dependence of the high-latitude ionosphere which results from the displacement between the geomagnetic and geographic poles.

\section{Introduction}

Recently, we combined a plasma convection model and an ionospheric-atmospheric composition model in order to study the dynamics of the high-latitude F-region. The plasma convection model, which is based on the work of Volland (1978), includes the offset between the geographic and geomagnetic poles, the tendency of plasma to corotate about the geographic pole, and a dawn/dusk magnetospheric electric field mapped to a circular region in the ionosphere about a center which is offset a few degrees in the antisunward direction from the magnetic pole (Meng et al, 1977). Equatorward of the circle the potential diminishes radially and varies inversely as the fourth power of sine magnetic co-latitude. The ionospheric-atmospheric composition model takes account of solar EUV radiation, energetic particle precipitation, diffusion, thermospheric winds, electrodynamic drifts, energy-dependent chemical reactions, and magnetic storm induced neutral composition changes (cf. Schunk and Raitt, 1980). The complete details concerning the combined plasma convection and ionospheric-atmospheric models are given by Sojka et al (1981a) and are not repeated here.

Our high-latitude F-region model produces time-dependent, 3-dimensional ion density distributions for the ions $\mathrm{NO}^{+}, \mathrm{O}_{2}{ }^{+}$, $\mathrm{N}_{2}^{+}, \mathrm{O}^{+}, \mathrm{N}^{+}$, and $\mathrm{He}^{+}$. Typically, we cover the high-latitude ionosphere above $42^{\circ} \mathrm{N}$ magnetic latitude and at altitudes between about 160 and $800 \mathrm{~km}$ for one complete day. In an initial application of this model, we studied the high-latitude F-region for winter, solar minimum, and low geomagnetic activity conditions (Sojka et al, 1981a, b). In a subsequent study (Sojka et al, 1981c), we compared the response of the winter F-region to both weak and strong plasma convection. For strong convection, we also studied the seasonal variations of the highlatitude ionosphere (Sojka et al, 1981d). One of the important results that emerged from these studies was that high-latitude ionospheric features, such as the 'main trough', the 'ionization ionizize 'tongue of ionization', and the 'aurorally produced ionization peaks', are a natural consequence of the competition be open the various chemical and transport processes known to be operating in the high-latitude ionosphere. We also found that tion features display a marked variation with season, convecpattern, and universal time.

In order to determine the validity of our model, we have compared model predictions with observations whenever possible. We compared plasma convection patterns predicted by our

Copyright 1982 by the American Geophysical Union. model with those observed concurrently at Chatanika, Alaska, and Millstone Hill, Massachusetts (Sojka et al, 1980). These two incoherent scatter facilities operated over the same period of four days in June 1978 and provided data sets that were averaged to 24 hours in order to minimize the effects of individual substorms. The two radar facilities observed different diurnal patterns of horizontal plasma convection velocities even though the measurements covered approximately the same range of magnetic latitudes, a feature predicted by the convection model. In general, there was good agreement between the convection model and the different diurnal patterns observed at Chatanika and Millstone Hill.

For solar minimum, winter, and low geomagnetic activity conditions, we have compared the electron density and ion compositional variations that were obtained from our model with the Atmosphere Explorer (AE-C) satellite data presented by Brinton et al (1978), and generally good quantitative agreement was obtained between theory and measurement (Sojka et al, 1981b). However, the AE data were not organized with respect to universal time (UT), and therefore, the large UT variation of electron density that our model predicts, which results from the displacement between the geomagnetic and geographic poles, could not be tested. To remedy this situation, we used the sun synchronous (fixed LT) nature and high time resolution of the ion density measurements from the DMSP F2 and F4 satellites to study the UT dependence of the high latitude ion density at $800 \mathrm{~km}$ (Sojka et al, 1982a). Both the long term variation of the ion density on a time scale of days, and the orbit by orbit variations at the same geomagnetic location in the northern (winter) hemisphere for the magnetically quiet time period chosen show good qualitative agreement with the UT dependence predicted by our theoretical model for similar geophysical conditions. We have also compared our predicted diurnal variations of plasma convection velocities and electron densities with specific measurements made at Millstone Hill on a geomagnetically quiet day near equinox (Sojka et al, 1982b), and again, good agreement was obtained between theory and measurement.

As noted above, the high-latitude ionosphere exhibits a marked UT variation owing to the displacement between the geomagnetic and geographic poles. In the geographic inertial frame, the plasma convection pattern rotates about the geographic pole while continually pointing toward the sun. During this rotation the high latitude ionosphere moves toward and then away from the sun, producing a UT variation in the photoionization rate. In a geomagnetic frame, the UT variation is also present and arises as a result of the motion of the terminator. An important consequence of this UT variation of the high latitude ionosphere is that ground-based observation sites at different longitudes will observe different diurnal variations of electron density. This is particularly relevant, since in the near future the high latitude ionosphere will be probed simultaneously by three incoherent scatter radars, including the European Incoherent Scatter Radar (ESICAT; geographic latitude, $70^{\circ} \mathrm{N}$, and longitude, $18^{\circ} \mathrm{E}$ ), Millstone Hill (geographic latitude, $43^{\circ} \mathrm{N}$, and longitude, $289^{\circ} \mathrm{E}$ ), and Chatanika (geographic latitude, $65^{\circ} \mathrm{N}$, and longitude, $145^{\circ} \mathrm{W}$ ). The purpose of this paper is to give an indication of the quantitative difference in the diurnal variations of the electron density which would be observed when the three radars operate simultaneously in the absence of substorm perturbations. 


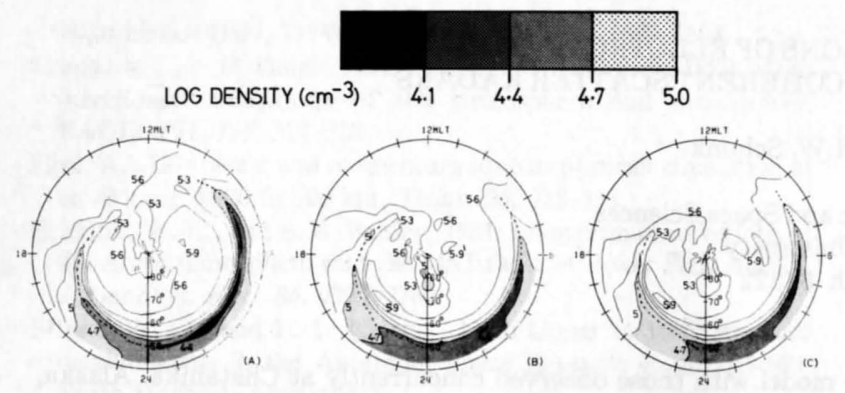

Figure 1: Winter electron density contours at $300 \mathrm{~km}$ for EISCAT (panel A), Chatanika (panel B), and Millstone Hill (panel C). The contours are displayed in a magnetic latitudeMLT frame; magnetic latitude varies from $40^{\circ}$ to $90^{\circ}$ as shown on the vertical scale, while MLT is indicated by tick marks at hourly intervals around the perimeter of the diagram. The contours are labeled in units of $\log _{10} \mathrm{~N}_{\mathrm{e}}\left(\mathrm{cm}^{-3}\right)$. The shading highlights the regions where $n_{e}<10^{5} \mathrm{~cm}^{-3}$, with the darkest shade representing the lowest density. The dashed lines show the locus of the trough minimum.

\section{Predicted Ion Densities at $300 \mathrm{KM}$}

For our calculations of the diurnal variation of electron density, we used our strong convection model (Sojka et al, 1981c,d). For this model, the total cross-tail magnetospheric potential was $90 \mathrm{kV}$ and the convection pattern was asymmetric with an enhanced convection cell in the dusk sector of the polar cap. Such an asymmetry in the convection electric field is commonly found in satellite electric field observations (Heppner, 1977) and in incoherent scatter radar observations (J. Foster; private communication). The important aspects associated with the model, namely convection trajectories, horizontal and vertical velocities, and auroral ionization sources, have been extensively discussed by Sojka et al (1981c) and are not repeated here. However, we note that the cross-tail magnetospheric potential was held constant for the duration of the calculations ( 1.4 days). Therefore, our predictions are relevant to an ionosphere unperturbed by substorms or to ionospheric data that have been averaged over several days to reduce substorm effects.

Our electron density predictions for the three incoherent scatter facilities will be displayed in a format commonly used to display radar data. All three facilities are able to obtain vertical scans of F-region electron density with a high time resolution (tens of seconds), whereas a vertical scan of the ion drift velocity is obtained with a slightly poorer time resolution. To scan a range of latitudes requires tens of minutes. However, a diurnal data set is collected over a 24-hour period. This long time period implies that the different facilities view the same local time sector of the ionosphere at different universal times. These UT differences are many hours for Chatanika, Millstone Hill, and EISCAT. Since substorms can occur frequently during the course of a day, one might conclude that any difference in electron density between two facilities measuring in the same MLT sector is attributable to substorms. However, as we show below, large electron density differences are expected even for substorm free periods.

\section{Winter Comparison}

Our time-dependent, 3-dimensional electron density distribution was 'viewed' from the Chatanika, Millstone Hill, and EISCAT radar sites as they corotated around the Earth for a 24-hour period. For convenience, in the following discussion we use the word 'observation' in reference to our model electron density distribution. Figure 1 shows contours of the winter electron density at $300 \mathrm{~km}$ as a function of dipole magnetic latitude and MLT for EISCAT (panel A), Chatanika (panel B), and
Millstone Hill (panel C). A comparison of the panels indicates that the three facilities should observe different diurnal varia. tions of electron density even if substorms are absent, owing to the displacement between the geomagnetic and geographic poles.

The differences between the three facilities are most evident with regard to 'observations' of the mid-latitude trough. Using the contour labeled 4.7 in the night sector to represent the trough, it is apparent that the three facilities observe a different MLT extent for the trough; 2000-0800 MLT for EISCAT, 2200-0530 MLT for Chatanika, and 2300-0630 MLT for Millstone Hill. Of the three facilities, the deepest trough is predicted in the morning sector for EISCAT (panel A).

In the polar region, the lowest electron densities are observed at different locations by the three facilities. For EISCAT the lowest polar electron densities are near the noon meridian, while for Chatanika and Millstone Hill they are near the midnight meridian in the vicinity of a polar depletion region described by Sojka et al (1981c). Overall, the lowest polar den. sities are observed from the Chatanika location (panel B).

For Chatanika (panel B) and Millstone Hill (panel C), a high density region extends from noon into the polar cap. This high density feature is cut by a region of significantly lower density in panel A (EISCAT). In the magnetic frame the terminator moves as a function of UT, and since the three facilities are at different longitudes they see the terminator move differently. Consequently, no clear density feature connected with the terminator (i.e., dawn-dusk alignment) is common to the three sites. For EISCAT (panel A), the 5.6 density contour extends from 1100 to $1800 \mathrm{MLT}$, while the equivalent contour for Chatanika (panel B) extends from 0900 to 1700 MLT, with a pronounced tongue of ionization extending into the polar cap near noon.

A density feature that is common to all three sites is the high density region associated with the auroral oval. This is particularly evident in the evening and early morning sectors $\left(55^{\circ}-65^{\circ}\right.$ latitude, $\left.1800-0600 \mathrm{MLT}\right)$.

\section{Equinox Comparison}

Figure 2 shows contours of the electron density at equinox for EISCAT (panel A), Chatanika (panel B), and Millstone Hill (panel C). Except for the change from winter to equinox, the model parameters and plotting format are the same as for Figure 1. The differences in the diurnal variation of electron density between the three facilities are not as great for equinox as for winter. As was found for winter, the largest MLT extent of the mid-latitude trough and the deepest trough are observed by EISCAT. The differences in the observed depth of the trough can be greater than a factor of 2 , especially in the morning sector.

In the polar cap, EISCAT observes a region of low electron density near the noon meridian, while Chatanika and Millstone Hill observe low densities predominantly near the midnight meridian. However, all three facilities observe a similar high density region in the evening-morning sector of the auroral oval. These comparisons are identical to those discussed earlier for winter conditions.
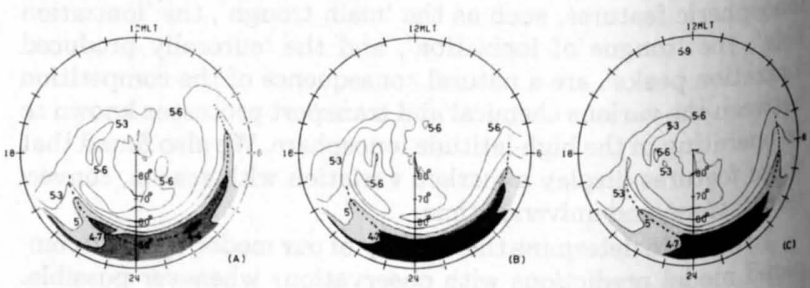

Figure 2: Equinox electron density contours at $300 \mathrm{~km}$ for EISCAT (panel A), Chatanika (panel B), and Millstone Hill (panel C). The plotting format is the same as for Figure 1. 


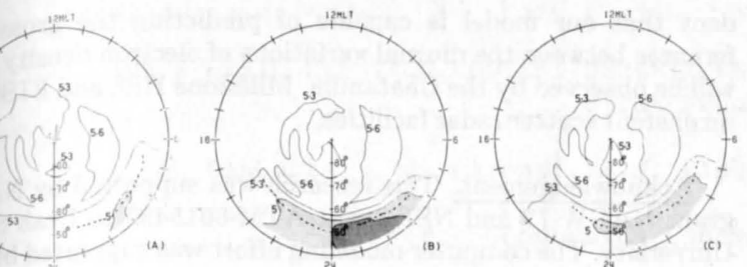

Figure 3: Summer electron density contours at $300 \mathrm{~km}$ for EISCAT (panel A), Chatanika (panel B), and Millstone Hill (panel C). The plotting format is the same as for Figure 1.

For equinox, the electron densities in the noon sectors are much more uniform than for winter. All three facilities observe a wide region covering most of the day where the electron density varies between $4 \times 10^{5}$ and $8 \times 10^{5} \mathrm{~cm}^{-3}$. This region is also observed to extend into the polar cap at each site, which was not the case in winter.

\section{Summer Comparison}

Figure 3 shows contours of the summer electron density at $300 \mathrm{~km}$ for EISCAT (panel A), Chatanika (panel B), and Millstone Hill (panel C). Except for the change in season, the model parameters and plotting format are the same as for Figures 1 and 2. During summer, when most of the high-latitude ionosphere is sunlit, the electron density distribution is more uniform. Also, the observed mid-latitude trough regions are smaller, confined to the midnight MLT sector, and the troughs are not as deep. The differences in observed trough features between the three sites that were found for winter and equinox are no longer the same in summer. Now, the deepest trough and the largest MLT extent of the trough are observed by Chatanika, whereas in winter and equinox EISCAT observed the deepest trough and the largest MLT extent of the trough.

The summer polar regions are very similar for the three sites. Electron densities between $2 \times 10^{5}$ and $4 \times 10^{5} \mathrm{~cm}^{-3}$ are found over most of the dayside and polar regions, which are noticeably lower than those found in this general region in both winter and equinox. This phenomenon of lower densities in summer, where the solar zenith angle is smaller, is referred to as the winter (or seasonal) anomaly (Banks and Kockarts, 1973). The densities are between a factor of 1.5 and 4 higher in winter and equinox than in summer.

\section{Predicted Winter Densities at 1800 MLT}

In the previous section, we compared the diurnal variation of electron density that would be observed by EISCAT,
Chatanika, and Millstone Hill in winter, equinox, and summer. In this section, the three sites are compared in more detail at 1800 MLT for winter conditions. For each site, the electron density will be displayed as a function of altitude and magnetic latitude. Such a display corresponds to data accumulated by an incoherent scatter radar in about 30 minutes.

Figure 4 shows contours of the winter electron density at 1800 MLT for EISCAT (panel A), Chatanika (panel B), and Millstone Hill (panel C). The contour and shading levels are the same as used in our previous figures. Also shown in the three panels of Figure 4 is the location of the F-region peak electron density, $\mathrm{h}_{\mathrm{m}} \mathrm{F}_{2}$ (indicated by dashed lines). It is apparent that at 1800 MLT the three facilities observe different electron density variations as a function of altitude and magnetic latitude, owing to the rotation of the geomagnetic pole about the geographic pole.

One feature is, however, common to all three sites, and that is the electron density variation associated with the auroral precipitation region between $66^{\circ}$ and $75^{\circ}$ latitude. In our model, the auroral oval and convection pattern are fixed in the magnetic frame, and therefore, each facility is expected to observe a similar electron density variation at low altitudes in the auroral oval. At higher altitudes in the auroral precipitation region, there is a complex electron density structure. Again, however, all three sites see similar density variations. This complex structure is highlighted by the variations of both $\mathrm{N}_{\mathrm{m}} \mathrm{F}_{2}$ and $\mathrm{h}_{\mathrm{m}} \mathrm{F}_{2}$, which result from changes in the transport properties across the auroral oval (cf. Sojka et al, 1981c).

Equatorward of the oval, the three facilities observe different density features. At $60^{\circ}$ latitude, $\mathrm{N}_{\mathrm{m}} \mathrm{F}_{2}$ is lowest for EISCAT, with a density below $10^{5} \mathrm{~cm}^{-3}$, and then $\mathrm{N}_{\mathrm{m}} \mathrm{F}_{2}$ increases to above $4 \times 10^{5} \mathrm{~cm}^{-3}$ on the equatorward side. The variation of $\mathrm{N}_{\mathrm{m}} \mathrm{F}_{2}$ that is observed by Chatanika is not as large, with the peak density remaining between $10^{5}$ and $4 \times 10^{5}$ $\mathrm{cm}^{-3}$. At altitudes below $250 \mathrm{~km}$, the three facilities observe very similar electron density variations because at these altitudes production and loss processes dominate and in winter this low altitude region is in darkness at all three sites. Therefore, the UT effect in our model, which is related to the motion of the terminator, is not important in this low altitude region. In contrast, at high altitudes differences are present both in density and scale height between the three sites. The scale heights observed at Chatanika equatorward of the auroral oval are typically $50 \mathrm{~km}$ less than those observed at either of the other two sites.

Even larger differences in the observed electron density occur poleward of the auroral oval. At Chatanika, $\mathrm{N}_{\mathrm{m}} \mathrm{F}_{2}$ reaches a minimum at $86^{\circ}$ at a density of about $10^{5} \mathrm{~cm}^{-3}$, while at this location the other two facilities observe densities of the order of $4 \times 10^{5} \mathrm{~cm}^{-3}$. Poleward of the oval, the high altitude densities
(A)

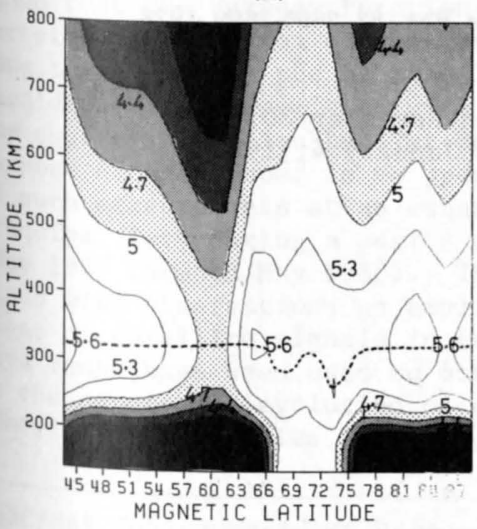

(B)

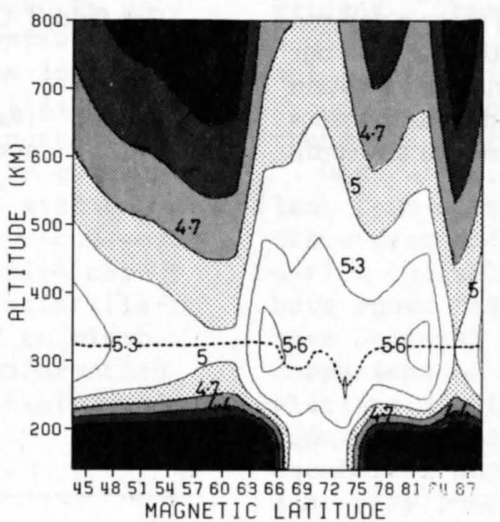

(C)

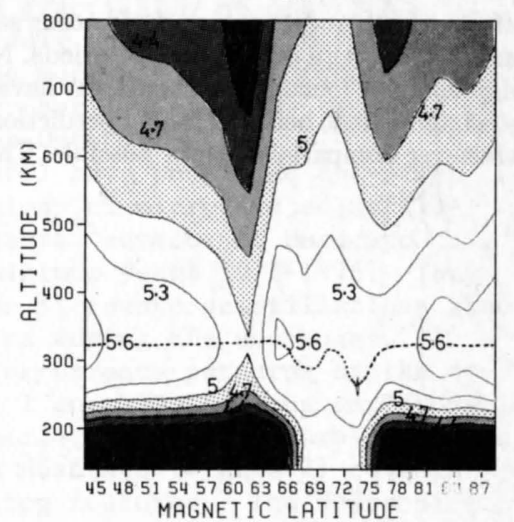

Figure 4: Winter electron density contours as a function of altitude and magnetic latitude at 1800 MLT for EISCAT (panel A), Chatanika (panel B), and Millstone Hill (panel C). The dashed lines show the variation of $h_{m} F_{2}$ as a function of magnetic latitude. The contouring and shading are the same as for Figure 1. 
differ by a factor exceeding 5 between the three sites, while below $250 \mathrm{~km}$ the densities are low and very similar owing to the lack of photoionization.

Both equatorward and poleward of the auroral oval, $h_{m} F_{2}$ is quite constant at about $320 \mathrm{~km}$. However, $\mathrm{N}_{\mathrm{m}} \mathrm{F}_{2}$ is variable and appears to have a fine scale latitudinal structure. This structure manifests itself in the contour plots as small closed regions. This structure is an integral feature associated with the UT dependent coupling between the solar EUV ionization source, the convection model, and the auroral ionization source. This fine structure would be further complicated if fine structure in the auroral precipitation fluxes were included in our model.

\section{Summary}

We have used a high-latitude ionospheric model to predict the diurnal variations of electron density that should be observed by the EISCAT, Chatanika, and Millstone Hill incoherent scatter facilities. Our calculations were for a strong convection model without substorms. Our electron density predictions are not intended for a detailed comparison with data, but should be used to obtain an indication of the quantitative differences in measured electron density that are expected when the three radars probe the high-latitude ionosphere simultaneously. These differences vary with altitude, latitude, local time, and season, and are associated with the UT dependence of the high-latitude ionosphere which results from the offset between the geomagnetic and geographic poles.

For our study we have found the following:

1. The three facilities should observe the greatest difference in electron density variations in winter.

2. The observed depth and extend of the mid-latitude trough should be different for the three facilities. The deepest trough and the greatest MLT extent of the trough should be seen by EISCAT in winter and equinox and by Chatanika in summer.

3 . The polar depletion regions are different in winter and equinox. EISCAT should observe the lowest electron densities in the noon sector, while Chatanika and Millstone Hill should observe them near the midnight sector.

4. At altitudes above the F-region peak, the three facilities can expect to observe electron density differences of up to a factor of 5 and scale height differences of up to $50 \mathrm{~km}$.

5. The altitude of the F-region peak density, $h_{m} F_{2}$, is sensitive to the convection pattern, but does not exhibit a significant UT variation.

Finally, we summarize some of the more important assumptions and limitations associated with our model predictions. First, we assumed a time-independent, magnetospheric electric potential distribution, and that this potential distribution could be mapped to F-region altitudes along geomagnetic field lines. We also assumed that the Earth's magnetic field could be adequately represented by an offset dipole, and we ignored the effects of substorms, which could occur several times a day and last for 2-3 hours during active periods. Nevertheless, with our high-latitude ionospheric model we have been able to obtain good agreement between model predictions and measurements whenever comparisons were possible. Therefore, we are confi- dent that our model is capable of predicting the gross dif. ferences between the diurnal variations of electron density that will be observed by the Chatanika, Millstone Hill, and EISCAT incoherent scatter radar facilities.

Acknowledgement. This research was supported by NASA grant NAGW-77 and NSF grant ATM-8015497 to Utah State University. The computer modeling effort was supported by the National Center for Atmospheric Research, which is sponsored by the National Science Foundation.

\section{References}

Banks, P.M. and G. Kockarts, Aeronomy, Academic Press, New York, 1973.

Brinton, H.C., J.M. Grebowsky, and L.H. Brace, The highlatitude winter F-region at $300 \mathrm{~km}$ : Thermal plasma obser. vations from AE-C, J. Geophys. Res., 83, 4767-4776, 1978.

Heppner, J.P., Empirical models of high-latitude electric fields, J. Geophys. Res., 79, 1046-1055, 1977.

Meng, C.-I., R.H. Holzworth, and S.-I. Akasofu, Auroral circle-Delineating the poleward boundary of the quiet auroral belt, J. Geophys. Res., 82, 164-172, 1977.

Schunk, R.W. and W.J. Raitt, Atomic nitrogen and oxygen ions in the daytime high-latitude F-region, J. Geophys. Res., 85, 1255-1272, 1980.

Sojka, J.J., J.C. Foster, W.J. Raitt, R.W. Schunk and J.R. Doupnik, High-latitude convection: Comparison of a simple model with incoherent scatter observations, J. Geophys. Res., 85, 703-709, 1980.

Sojka, J.J., W.J. Raitt and R.W. Schunk, A theoretical study of the high-latitude winter F-region at solar minimum for low magnetic activity, J. Geophys. Res, 86, 609-621, 1981a.

Sojka, J.J., W.J. Raitt, and R.W. Schunk, Theoretical predictions for ion composition in the high-latitude winter F-region for solar minimum and low magnetic activity, J. Geophys. Res., 86, 2206-2216, 1981b.

Sojka, J.J., W.J. Raitt and R.W. Schunk, Plasma density features associated with strong convection in the winter high-latitude F-region, J. Geophys. Res., in press, 1981c.

Sojka, J.J., R.W. Schunk and W.J. Raitt, Seasonal variations of the high-latitude F-region for strong convection, J. Geophys. Res., in press, 1981d.

Sojka, J.J., W.J. Raitt, R.W. Schunk, F.J. Rich and R.C. Sagalyn, Observations of the diurnal dependence of the high-latitude F-region ion density by DMSP satellites, J. Geophys. Res., in press, 1982a.

Sojka et al, A comparison of model predictions and Millstone Hill observations of the high-latitude electron density, in preparation, $1982 \mathrm{~b}$.

Volland, H., A model of the magnetospheric electric convection field, J. Geophys. Res., 83, 2695-2699, 1978.

(Received November 30, 1981; accepted January 4, 1982.) 